Bryant University

Bryant Digital Repository

$1-2009$

\title{
Young Children's Access and Use of Computers in Family Child Care and Child Care Centers
}

\author{
Nanci Weinberger \\ Bryant University \\ Traci Anderson \\ Phyllis Schumacher \\ Bryant University
}

Follow this and additional works at: https://digitalcommons.bryant.edu/apjou

\section{Recommended Citation}

Weinberger, Nanci; Anderson, Traci; and Schumacher, Phyllis, "Young Children's Access and Use of Computers in Family Child Care and Child Care Centers" (2009). Applied Psychology Journal Articles. Paper 34.

https://digitalcommons.bryant.edu/apjou/34

This Article is brought to you for free and open access by the Applied Psychology Faculty Publications and Research at Bryant Digital Repository. It has been accepted for inclusion in Applied Psychology Journal Articles by an authorized administrator of Bryant Digital Repository. For more information, please contact dcommons@bryant.edu. 
Computer Use in Child Care 1

Young Children's Access and Use of Computers in Family Child Care and Child Care Centers 


\title{
Computer Use in Child Care 2
}

\begin{abstract}
Forty eight family child care providers and thirty seven center-based providers completed surveys about the availability and use of computers for children in their care. In addition, the providers were asked about their attitudes towards technology and their own computer skills. The impact of setting type on computer placement and rules about their use did not differ very much by setting type. Several factors were associated with the amount of time children were reported to use the computers. Overall, it appears that child care providers had developmentally sensitive guidelines for fostering computer use in both child care settings.
\end{abstract}

Keywords: Children, child care, child care providers, computers 


\section{Computer Use in Child Care 3}

The potential benefits and problems of technology in young children's lives in school and home settings has been of interest to a wide group of researchers and policy makers (e.g., Espinosa, Laffey, Whittaker, \& Sheng, 2006; Wartella, Caplovitz \& Lee, 2004; Alliance for Childhood, 2000; Shields \& Behrman, 2000; Ba, Tally \& Tsikalas, 2002). In the current study, the context regarding the access and use of computer technology for young children attending family child care homes (FC) and child care centers (CC) was investigated.

In a report on contemporary American children's exposure to electronic media, young children are characterized as "growing up immersed in media" (Rideout, Vandewater \& Wartella, 2003, p. 4). This immersion is based in part on children's use of computers. Parents reported that nearly half (48\%) of children under six have used a computer, with $18 \%$ using a computer daily. More parents of young children perceive computer use positively as compared with other electronic media sources, such as television (e.g., $72 \%$ of parents report computers "mostly help" children, while only $43 \%$ report televisions "mostly help", Rideout, Vandewater \& Wartella, 2003).

Not surprisingly, there has been more research on school age children's use of technology as compared with preschool age children's use. Children's use of computers in educational settings has been widely studied (e.g., Yelland, 2005; Roschelle, Pea, Hoadley, Gordin and Means, 2000). In some studies, both school and home use have been researched, as found in the large scale study on kindergarten and first grade access and use of computer resources (Rathbun, West and Hausken, 2003). Notably, technology is increasingly available to younger and younger children, including toddlers (Robinson, 2003; Jordan and Wood, 2001) and infants (Roderman, 2002). Some have argued that a wide range of interactive media, including computers, are being especially targeted towards the youngest of children (Schmidt, Bickham, King, Slaby, Branner \& 


\section{Computer Use in Child Care 4}

Rich, 2005). A comprehensive review of the research literature on interactive media in children's lives revealed that there were a limited number of studies that focus on preschool children (Wartella, O'Keefe and Scantlin, 2000). A great deal of research on preschool children's computer use has been based on their use in the home (e.g., Fineberg and Cassidy, 2003). Since a significant proportion of American children under five years of age with employed parents attend either child care centers or family child care homes, the role of computers in these particular settings needs to be more closely examined (Capizzano, Adams, \& Sonenstein, 2000). While child care centers and family child care homes both provide care for infants, toddlers and preschoolers, the two types of settings differ enough from one another to suggest that computers may not be made available to children in the same ways in both settings. These distinctions will be addressed in the current study.

As found with research on earlier forms of technology, research on children's use of computers has addressed both its potential risks and rewards. Some researchers have addressed concerns regarding the potentially negative health effects associated with strain from inappropriately positioned computers for young children (Gillespie, 2002). For example, research on computer access in inclusive child care centers demonstrate that when computers were available for children, they were infrequently located in areas which were easily accessible and designated specifically as computer areas (Martin, Forsbach-Rothman and Crawford, 2004). In addition, some organizations, such as the Alliance for Childhood (2000), suggest that computers may contribute to other childhood problems related to sedentary habits arising from computer use. The Alliance for Childhood also argues that computers "distract" professionals from properly addressing children's educational needs. 


\section{Computer Use in Child Care 5}

A different perspective can be seen in the position statement from National Association for the Education of Young Children (NAEYC) regarding the use of technology in early childhood educational settings, including child care settings (1996). The NAEYC regards the use of computers as both inevitable and potentially beneficial for children. This regard for using computers comes with some caution as the NAEYC urge early childhood educators to responsibly include technology in developmentally appropriate ways (NAEYC, 1996). Educators are reminded that "computers supplement and do not replace highly valued early childhood activities and materials" (1996, NAEYC Position statement, 1). This position is supported in Yelland's (2005) review of the research literature on the use of computers in early educational settings. The promotion of literacy and numeracy in early childhood has been supported by integrating computer technology into the literacy and numeracy curriculum. Those working with young children have described several specific ways in which technology can be used to support the emergence of literacy for very young children, including those less than 3 years old (Robinson, 2003).

In the NAEYC position statement it is noted that supporting teacher training is an essential element of making the best use of technology. This is consistent with a study on computer access in inclusive child care centers (Martin, Forsbach-Rothman and Crawford, 2004). The authors argued that these child care teachers did not have the proper training to optimize the use of technology in inclusive child care centers. Although computers are found increasingly in early childhood classrooms, they are not always embraced by teachers (Bewick \& Kostelnik, 2004). Poorly integrating technology in a child care setting can be the outcome of many factors, including, limited teacher technology skills and negative teacher attitudes towards technology. In addition, teacher beliefs about the benefits and drawbacks of computer use with 


\section{Computer Use in Child Care 6}

children are likely to affect what is made available to children. These associations between provider factors and computer availability may be particularly strong in family child care homes, where the provider is typically the only person responsible for setting up the program and delivering services. In the case of child care centers, there may be many people involved in decision making, such as the owner (corporate or otherwise), the director, curriculum coordinator, and lead teachers.

In the current study access to computer technology in two child care settings for young children (i.e., family child care homes and child care centers) was measured. Participant responses to survey questions will help to answer three broad conceptual questions. The first question we ask in this study is how are computers made available to children in the two settings? This question concerns the physical placement of computers in the setting as well as the rules and guidelines for their use. Numerous studies report that there is a "mismatch" between older children and computer workstations found in school settings (Gillespie, 2002; Bennett, 2002). Both of these authors suggest that home settings may be even more problematic given that the mix of computer users includes adults and children and therefore computer work stations are not exclusively set up for children. Our first hypothesis related to this question is that computer areas in child care centers will be better positioned for use than computer areas in family child care homes. The reason for this expectation is that one distinction between the two setting types is that centers have space that is organized by age groupings and family child care homes have mixed aged groupings of children (and the family itself may also use the child care space during non-business hours). Thus, in child care centers the physical placement will more likely have child-centered seating arrangements that are safe and easy to use. 


\section{Computer Use in Child Care 7}

The second hypothesis related to computer access is that older preschool children in both settings will have greater access to use computers including less need for permission, less adult assistance, greater access to computer peripherals and more time allotted as compared with younger preschool children.

The second question we ask in this study is how much time do different children use computers in these two types of child care settings? Our first hypothesis related to this question is that older preschool children will use computers more than younger children in both settings. Given the recent software trend to target products towards younger children, including toddlers and infants, it is expected that in child care settings that have computers available, there will be some modest use of computers by toddlers and infants. Only minimal use is expected given the time constraints and supervision demands of child care providers. Our second hypothesis related to this research question is that there will not be gender differences in the amount of computer use in the two different child care settings. While boys and girls have been reported to use computers in different ways, for example selecting different software programs, the same children have been reported to use computers at equivalent rates (Gillespie, 2002) including equivalent amount of time for each internet session (Lynch \& Juang, 2003). In addition, other findings on preschoolers' use of computers in the home suggest that boys and girls' use is similar (Li \& Atkins, 2004).

The final research question is what is the relationship between children's computer access and use to provider characteristics? It is expected that differences in access and use will be related to provider background. Our first hypothesis related to this question is that providers with higher levels of education, higher levels of computer use and proficiency, and more positive attitudes towards computers and technology will provide greater access for computer use to the 


\section{Computer Use in Child Care 8}

children in their care than other providers. Our second hypothesis is children in the care of providers with higher levels of education, higher levels of computer use and proficiency, more positive attitudes towards computers and technology will use computers more often than other children.

\section{Method}

\section{Participants and Sampling Protocol}

Participants were obtained from a list of all child care centers $(n=121)$ and family child care homes $(n=1,317)$ in Rhode Island licensed by the state's Department of Children, Youth and Families. Letters were sent to all 121 child care centers and an equal number of family child care homes who were randomly selected from the list. After the initial mailing, a second mailing was done to increase the representation of family child care providers. Identical surveys were mailed out to 200 additional family child care providers who were not previously contacted.

Child care providers were encouraged to participate even if they did not provide computers in their child care setting. The letters included an invitation to anonymously participate by filling out and returning the enclosed survey with a self-addressed, stamped envelope. An informed consent letter and a five dollar gift certificate to Dunkin Donuts were also included in each letter.

The final sample included 85 usable surveys. Thirty seven of the surveys were from center-based child care providers (31\% response rate) and 48 were from family child care providers (15\% response rate). Of these participants, 63 providers had computers available for children to use (37 family child care providers and 26 center providers). All participants but one reported to be female and participants' ages ranged from 25 to $62(\underline{\mathrm{M}}=41.44, S D=9.35)$. Regarding ethnicity, 79 participants (92.9\%) listed their primary racial/ethnic identity as 


\section{Computer Use in Child Care 9}

White/European American," 3 (3.5\%) listed "Latino/Hispanic," 2 (2.4\%) listed "Black/AfricanAmerican," and 1 (1.2\%) listed "Asian/Asian-American." Participants' levels of education varied; $11(12.9 \%)$ were high school graduates, 23 (27.1\%) had attended some college, 10 (11.8) had earned associate's degrees, $31(36.5 \%)$ had earned bachelor's degrees, and $10(11.8 \%)$ had earned graduate degrees. Of those participants who attended college and reported their major, 22 (25.9\%) majored in special education, 14 (11.5\%) majored in child- or human development, 9 (10.6\%) majored in a related social science (e.g., psychology, sociology), and 25(29.9\%) reported majoring in "other."

Participants reported having worked in the child care field for one-half to 41 years $(M=$ 13.67 $S D=7.67$ ) and having worked in their current child care positions for one-half to 31 years $(\underline{M}=9.53, S D=7.08)$. The positions held by participants included family child care provider $(n$ $=48[56.5 \%])$, child care center director $(n=26[30.6 \%])$, child care center head teacher $(n=3$ [3.5\%]), child care center owner $(n=3[3.5 \%])$, "other" $(n=5[5.9 \%])$. Providers in family child care homes and centers took care of infants, preschoolers and some school age children. The gender and age distribution of children by setting type can be seen in Table 1.

\section{Measures}

The survey contained seven sections, three of which were adapted from previously used scales on technology usage in education. All child care providers were asked to complete the first four sections. The last three sections are relevant only if there are computers for children in the child care setting and therefore only providers who have computers available for children in their care were asked to complete the entire survey.

I. Level of Technology Adoption. Participants' levels of technology use were assessed using the Concerns-Based Adoption Model Scale (Loucks, Newlove \& Hall, 1975, as cited in 
Knezek, Christensen, Miyashita \& Ropp, 2000). The scale focuses on behaviors associated with making progress towards technology adoption in education. In the current study, the scale was adapted to address technology adoption in terms of providers "work with children" rather than teachers' use in traditional classroom settings. This single item scale includes 8 levels of technology use ranging from non-use to renewal. The three lowest levels of adoption describe individuals who have not yet used technology in their work with children. The next two levels of technology adoption describe individuals who use technology in limited ways in their work with children and this technology use does not involve significant reflection or effort. Finally, the highest three levels of technology adoption describe users who have a dynamic approach of revision and evaluation in their use of technology in their work with children.

II. Technological Proficiency. Participants' levels of technological proficiency were measured using an adapted version of the Technology Proficiency Scale Self Assessment Scale (Ropp, 1999 as cited in Knezek, Christensen, Miyashita, \& Ropp, 2000). This 5-point (1= strongly disagree to $5=$ strongly agree) scale addresses one's proficiency using electronic mail, the internet, integrated applications, and integrating technology into teaching. The scale has been used previously by teachers to assess their own proficiency with technology and computers, specifically. It has also been used to show teachers a variety of ways that their computer skills can be applied to classroom uses. For this study, 8 additional items were included to the existing 20 items. These new items addressed proficiency with peripheral technology, such as scanners, printers and digital cameras, and common computer uses lacking from the original scale such as making on-line purchases and playing computer games. Because new items were added to this measure the dimensionality of the revised 28-item scale was assessed using a principle components factor analysis. The factor solution and scree test indicated the scale was 
unidimensional and Cronbach's alpha is .964.

III. Perceived Impact of Technology On Children. To assess participants' perceptions of technology's impact on children, the researchers developed a 17 item 6-point Likert type scale (1 $=$ strongly disagree to $5=$ strongly agree). The scale included such items as "I feel computers provide unique experiences," "I feel computers confuse fantasy and reality," "I feel computers foster good learning habits," and "I feel computers are safe" (see Appendix XX for the full scale). The researchers assessed scale dimensionality with a principle components factor analysis and both the factor solution and scree test indicated the scale was unidimensional. However, the factor analysis and scale reliability indicated a problem with one item that, upon further review, did not fit as well conceptually with the other items. Thus, one item was dropped from subsequent analyses. The Cronbach's alpha is .90 for the 16-item scale.

IV. Information Technology Attitudes. The Teachers' Attitudes toward Information Technology Scale was used to measure the child care providers' attitudes toward technology. This scale has been used in prior research to assess teachers' attitudes towards a variety of computer-related technologies (Knezek \& Christensen, 1998 as cited in Knezek, Christensen, Miyashita \& Ropp, 2000). Questions about the providers' attitudes include the following five areas: electronic media, the internet, interactive media programs, computer use for professional work and computer use for children in the classroom. For each area, there are 10 identical semantic differential adjective pairs, on a 7 point scale. In the current study the scale was modified to ask about children in a child care setting rather than a classroom setting. Also, an additional adjective pair was added (i.e., relaxing/stressful) to the list that included items such as boring/interesting and important/unimportant. 
V. Ergonomics of Computer Placement. In order to describe if computers are placed appropriately within each child care setting several relevant questions were created. The questions are based, in part, from recommendations of the Ergonomics for Children and Educational Environments of the International Ergonomics Association (http://education.umn.edu/kls/ecee/). There are 9 items about placement, including items on lighting, electrical cords, placement with respect to children's eyes and feet. For each item a 5 point Likert scale $(1=$ strongly disagree to $5=$ strongly agree $)$ was used.

VI. Guidelines for children's use of computers. In order to describe the degree of access to computers, questions about the providers' rules for computer use were included here. The questions were about getting permission, unassisted use, time limits, supervision during use for each of the following age groups: $1,2,3,4$, and 5 year olds. In total there were 37 items using a 5 point Likert scale $(1=$ strongly disagree to $5=$ ranging from strongly agree to strongly agree $)$.

VII. Children's use of computers in care. This section was included to measure how much time young children in care use computers. Providers were asked to include information about groups of children based on age and gender. Therefore, providers were asked to give estimates of use based on the average child use given a typical day. There were 12 items regarding the average amount of computer use for girls and boys for the following age groups was collected: under 1, 1,2,3, 4, and 5 year olds.

Results

\section{Computer Access}

Our first broad question of inquiry was how are computers made available to children in the two child care settings? We hypothesized about the placement and rules regarding computers in these settings. Our first hypothesis was that computer areas in child care (CC) centers will be 
better positioned for use than computer areas in family child care (FC) homes. Family child care providers more strongly agreed $(\underline{\mathrm{M}}=3.78)$ that children use the same computer as the provider as compared with center-based providers $(\underline{M}=1.71, \mathrm{t}=6.175, \mathrm{p}=0.000)$. With respect to the questions about the Ergonomics of Computer Placement, the overall MANOVA was significant $(\mathrm{F}[1,61]=2.82, \mathrm{p}=.000)$ with only one of the 9 questions being significantly different by center type. Center-based providers more strongly agreed $(\underline{M}=4.038)$ that the children's feet could reach the ground or another surface when using the computer as compared with family child care providers $(\underline{\mathrm{M}}=2.892, \mathrm{~F}[1,64]=11.73, \mathrm{p}=.001)$. Based on these limited differences, the hypothesis was not supported. Although there was strong evidence that the children in family care and not in child care centers used computers that were also used by the child care providers.

Paired t-tests were used to test our next hypothesis that older preschool children (i.e., 4-5 year olds) would have greater access to computers as compared with younger preschool children (i.e., 1-3 year olds) in both settings. Higher scores indicated that the providers more strongly agreed that children needed permission, adult assistance and limits on allotted time for computer use. Higher scores on the question about computer peripherals indicated providers more strongly agreed that items such as CD-ROMs are readily available to children. There were no significant differences about the rules for younger and older children for either the need for permission $(\underline{\mathrm{M}}=$ 4.08) or the amount of allotted time $(\underline{\mathrm{M}}=3.91)$. There were, however, significant differences about the rules for older and younger preschool children needing adult assistance for computer use and access to computer peripherals. Older children were less likely $(\underline{M}=3.32)$ to be required to have adult assistance than younger children $(\underline{\mathrm{M}}=4.19, \mathrm{t}=6.53, \mathrm{p}=.000)$. In addition, older children were reported to have greater access $(\underline{M}=2.51)$ to computer peripherals as compared 
with younger children $(\underline{\mathrm{M}}=1.72 ; \mathrm{t}=5.84, \mathrm{p}=.000)$. Thus, we have mixed support for this hypothesis about age differences in computer access.

\section{Amount of use}

In addition to examining computer access in these two setting types, we wanted to see how much time different children use the computers. We hypothesized that older preschool children would use computers more than younger children in both settings. We expected only minimal use of computers by children under the age of 1 . The amount of time for the 48 boys and 43 girls under the age of 1 was reported to be zero. A paired t-test indicated significant differences in the average amount of time older $(\underline{M}=20.94$ minutes per day) and younger preschool children $(\underline{M}=12.98$ minutes per day; $\mathrm{t}=6.287, \mathrm{p}=.000)$ used the available computers, also supporting this hypothesis.

With respect to gender, we hypothesized that there would be no gender differences in the average amount of time children use computers. A paired t-test supported this hypothesis; there were no significant differences between the reported number of minutes boys $(\underline{M}=16.12)$ and girls $(\underline{\mathrm{M}}=15.96)$ used the computers each day.

Upon closer examination independent t-tests revealed that the amount of time children used computers sometimes differed by setting type. It was found that children in family child homes spent more time using computers as compared with children in child care centers (FC, $\underline{\mathrm{M}}$ $=19.12 ; \mathrm{CC}, \underline{\mathrm{M}}=14.08, \mathrm{t}=2.335, \mathrm{p}=.0231)$. Girls, but not boys, were reported to spend more time using computers in family child care homes as compared with the girls in centers $(\mathrm{FC}, \underline{\mathrm{M}}=$ 19.58, $\mathrm{CC}, \underline{\mathrm{M}}=13.70, \mathrm{t}=2.657, \mathrm{p}=.010)$. In addition, older preschool children, but not younger preschool children, spent more time using computers in the family child care homes as compared with older preschool children in centers $(\mathrm{FC}, \underline{\mathrm{M}}=23.48, \mathrm{CC}, \mathrm{M}=15.77, \mathrm{t}=2.711, \mathrm{p}$ 
$=.009)$. The differences found in the amount of time children used the computers occurred even though there were no differences in how much allotted time children were allowed to use the computers based on their age for either family child care providers or center based providers $(\mathrm{FC}$, younger $\underline{\mathrm{M}}=4.11$, older $\underline{\mathrm{M}}=3.94, \mathrm{t}=1.183, \mathrm{p}=.245 ; \mathrm{CC}$, younger $\underline{\mathrm{M}}=3.68$, older $\underline{\mathrm{M}}=$ $3.76, t=-.439, \mathrm{p}=.665)$. Finally, older girls spent more time using computers in family child care homes than older girls in centers $(\mathrm{FC}, \underline{\mathrm{M}}=24.67 ; \mathrm{CC}, \underline{\mathrm{M}}=15.23, \mathrm{t}=3.204, \mathrm{p}=.002)$.

\section{Provider characteristics and computer access and use}

The final research question asked what is the relationship between provider characteristics and computer access and amount of time children use computers? The provider characteristics of interest included level of education, self-ratings of their own technology skills, and their attitudes toward technology. A summary of these provider characteristics are described below and can be seen in Table 2. Differences by center type were assessed by a MANOVA, which was significant overall; the specific differences are noted in the table.

\section{Educational Level}

The educational level of the providers was significantly different by setting type as noted on a five-point scale. Center providers had on average a college degree while family child care providers had on average completed some college courses.

\section{Level of Technology Adoption}

This single item scale includes 8 levels of technology use ranging from non-use to renewal. Providers in the two settings responded similarly, with only $17.6 \%$ of respondents indicating they were at one of the three low levels of non-use. Two of these lowest levels of technology adoption include the intention of use in the future. More respondents indicated they were at the two middle levels of technology adoption (29.4\%) as compared with the three lowest 
levels of adoption. These respondents use technology in limited ways in their work with children and this technology use does not involve significant reflection or effort. Finally, the largest proportion of respondents was at the highest level of technology adoption (i.e., 50.6\%). These individuals have a dynamic approach of revision and evaluation in their use of technology in their work with children.

\section{Technology Proficiency}

Consistent with the previous measure, the providers in both settings reported relatively high levels of confidence in their computer skills such as being able to send e-mail attachments and other methods of integrating technology into teaching.

\section{Perceived Impact of Technology on Children}

The providers in both settings reported positive perceptions about the impact of technology on children's lives. For example, the providers agreed that computers can foster good learning habits.

\section{Information Technology Attitudes}

Unlike the other technology measures, differences were found between center-based providers and family child care providers regarding their attitudes about three of five uses of technology. Center-based providers more positively rated e-mail and internet use as compared with family child care providers. In addition they had a more positive view about their professional use of computers than did family child care providers.

With respect to our hypotheses, we expected that providers with higher levels of education, technology adoption, computer proficiency and more positive attitudes about the impact of technology on children and more positive attitudes towards information technology generally, would provide greater access for computer use to the children in their care as 
compared with other providers. We assessed this claim by finding bivariate correlation coefficients for the variables in question.

Contrary to our hypothesis, education was inversely related to two computer access measures. Education was inversely associated with needing permission prior to computer use for older preschool children $(r=-.288, \mathrm{p}=.022)$. Also, education was inversely associated with requiring all children get adult assistance prior to computer use $(r=-.344, \mathrm{p}=.005)$. However, education was unrelated to the amount of time allotted for computer use and the availability to computer peripherals.

Level of technology adoption and attitudes about the impact of technology on children were not associated with any of the measures of computer access. However there was a positive association between providers' technology proficiency and one measure of computer access. Computer proficiency was positively associated with requiring adult assistance when young preschool children used the computers $(r=.310, \mathrm{p}=.022)$.

Nevertheless, some associations with providers' attitudes about information technology, and children's access to computers were found. There was an inverse relationship between positive attitudes about children using computers and children needing adult assistance with computer use $(r=-.256, \mathrm{p}=.041)$. Also, there was an inverse relationship with positive attitudes towards the internet and older preschool children needing adult assistance with computer use $(r=$ $-.277, \mathrm{p}=.019)$. Finally, attitudes regarding multimedia technology was inversely related to older children both needing permission for computer use $(r=-.255, \mathrm{p}=.044)$ and time limits for computer use $(r=-.274, \mathrm{p}=.029)$. Taken together, our hypothesis about the relationship between provider characteristics and computer access was not supported. 
In addition to examining the relationship between provider characteristics and computer access we also hypothesized that the same provider characteristics would be associated with greater levels of computer use by children. Contrary to our hypothesis, there were few associations between provider characteristics and the amount of time children were reported to use computers. Notably, as with computer access, there was a significant inverse relationship between provider education and the amount of computer use for all preschool children $(r=-.283$, $\mathrm{p}=.033$ ). Also, provider views about the impact of technology on children's lives was positively associated with the amount of time older preschool children used computers $(r=.284$, $\mathrm{p}=.048$ ). Thus, the hypothesis about the relationship between provider characteristics and computer use was only very modestly supported.

\section{Discussion}

As predicted, boys and girls have comparable levels of computer use and older preschool children spend more time using computers than younger preschool children. There was only limited support, however, for the hypothesis regarding age differences in access to computers. Additionally, the appropriate placement of computers did not differ very much by child care setting as predicted. Finally, our hypotheses about the relationship between provider characteristics and computer access and computer use ran counter to our expectations in interesting ways.

As previously described, the two types of care settings have some underlying differences but the consequences of these differences were not as expected. The physical arrangement of the computers was reported to be relatively similar with respect to ergonomic considerations in spite of the overlapping use of computers by children and providers in family child care homes. The one exception about positioning is that children in family child care are less likely to have their 
feet reaching the ground or on a foot rest. It may be that child care providers are becoming more aware of optimal computer workspace arrangements as the growing body of research about the ergonomics of products used by children is becoming more available (see Lueder and Rice, 2008). In addition to the actual placement of computers in workspaces there remains a need for children to be reminded to adjust their seats, monitors and keyboards as well as to take breaks (http://ergo.human.cornell.edu/).

Older preschool children in both settings were less likely to be required to have adult assistance when using computers as compared with younger preschool children even though the providers required children of all ages to ask permission to use the computers and allotted all children the same amount of time to use them. This too may reflect awareness on the part of the providers that using computers can be valuable to children but require developmentally appropriate arrangements for use. In other words, the computers are made available but with graduated independent use according to age.

Interestingly, children in family child care, especially older girls, were reported to use the computers more than their counterparts in centers. This is an unexpected finding since the providers in the two settings did not differ in the amount of allotted time allowed for younger and older preschool children and were both allotted a limited amount of time. We did not ask about allotted time by gender so we don't know if there were differences in the amount of allotted time for boys and girls. Beyond provider rules, children also determine to some extent how often they will use the computers. It is likely that older children have a competitive advantage over younger children in commandeering a computer to use. Notably, in family child care settings each child has fewer age-mates and therefore less direct competition for this resource. Moreover, there are fewer same-gender peers to compete with in this setting. Recent 
research on early competitive game playing behavior with kindergarten children found that girls in same gender groups of four compete much less than when girls played with boys and when boys played in same or mixed gender groupings (Weinberger \& Stein, in press). This suggests that group composition can affect how actively children compete. Thus, even when there are multiple computers available, as often found in centers, the computer area may be intimidating to enter for some children because of the existing peer composition. The computer area within family child care homes may be relatively less intimidating, especially for older girls as compared with the computer areas in centers. While the providers may lay the groundwork for children to use the computers, other factors such as group composition are also likely to be involved in children's actual use.

Our specific predictions about provider characteristics were not supported. However, we did find that in some cases provider characteristics had meaningful associations with children's access and use of computers in these child care settings. Provider education was associated with computer access rules and actual use more than any other provider characteristic. It was inversely associated with requiring permission prior to computer use for older preschool children. So while there was a general agreement among providers that there is a need for permission prior to computer use, we can see that providers with the higher levels of education place fewer demands on needing permission for the more independent, older preschool children. Education was also inversely related to requiring children to get adult assistance prior to computer use. Two other provider characteristics were also inversely related to requiring children to get adult assistance prior to computer use. There was a negative correlation between requiring adult assistance for older children and attitudes about the web. There was also a negative correlation between requiring adult assistance and attitudes about children using 
computers. Only a single provider characteristic, computer proficiency, was positively associated with requiring adult assistance, at least in the case of young children. Thus, while providers may agree that children need adult assistance while using computers, the providers with higher levels of education and more positive attitudes about technology had fewer restrictions about needing adult assistance. Yet, the providers with more specific computer skills were more likely to have greater restrictions about the need for adult assistance but only for young preschool children. These children in particular may miss out on the potential benefits of using the computer without adult assistance. More education and more positive attitudes about technology help with being flexible with older children; while having specific computer skills appear to help providers see the need for adult support with less independent children. It is reasonable to expect teacher assistance to matter. In a recent review article, McCarrick \& Lee (2007) noted that preschool children in controlled experiments had different performance outcomes based on how involved the teachers were in computer-based interactions. Children in teacher-mediated groups as compared with children in groups with less teacher involvement performed better not only on computer tasks but (non-linguistic) cognitive tasks as well. In the current study, we don't know how involved the child care providers were in their technologybased interactions with children but we do know that they valued adult assistance and adult assistance was applied in developmentally sensitive ways.

There were additional associations between provider characteristics and other rules about computer access. While the providers didn't have different rules about permission and allotted time based on children's age it was found that the providers' attitudes about multimedia tools was inversely related to both the allotted time for computer use and the need to ask for permission prior to computer use for the older preschool children. In other words, the providers 
with relatively more positive attitudes about multimedia tools had fewer time constraints and requirements for permission for older children while this association was not noted for younger children. By examining provider characteristics along with provider rules by age we can see that there appears to be some developmental sensitivity regarding these rules.

With respect to how much time the providers reported children used the computers there were two correlated provider characteristics. Consistent with the access variables, education was inversely associated with the amount of time children used computers. Not surprisingly, when providers allow for more time for children to use computers, children use computers more often. Perhaps the more educated providers are also sensitive to the consequence of children's response to this freedom of computer use being associated with increases in time spent on the computer. This may in turn shape their rules about computer use, leading them to provide computer time in more limited ways for children in care partially explaining the inverse relationship of provider education and amount of computer time. In addition, more educated providers may also offer more alternative opportunities for children's activities, thereby interfering with the amount of time children in their care use the computers. Recommendations about limiting computer and other screen time to two hours a day maximum (as outlined by the American Academy of Pediatrics) has been supported by research in educational settings (Clements \& Sarama, 2003). Yet, rigid time limits (of 10 minutes or less) on appropriate computer use can have negative outcomes such as, "generating hostility and isolation and restrict communication, creativity, and exploration" ( Clements \& Sarama, 39). In the current study, the providers present a balanced picture of computer availability where children can use computers with some developmentally appropriate restrictions in place. 
The only other provider characteristic associated with the amount of time using computers is the perceived impact of technology score. Perceived impact of technology was positively associated with the amount of time older preschool children used computers. As noted previously, the providers did not have different rules about the amount of allotted time to use computers for younger and older preschool children. However, older preschool children spend more time using computers. Perhaps the providers' role in this age difference comes from their views about the impact of technology, with more positive views being linked to facilitating the more developmentally prepared children to use computers more often.

Our predictions about provider characteristics were not supported and the associations that were revealed between provider characteristics and computer access and use were modest in scope. Nevertheless the findings are still informative. It is worth noting that other research has also found that when K-12 teachers have generally positive attitudes towards technology their attitudes have only a small impact on the amount of computer use (Judson, 2006). In Judson's research teacher attitudes toward technology were not correlated with observed technology related teaching practices. In another recent study with elementary school teachers with recent, high quality technology training, it was found that other factors were related to student computer use (Franklin, 2007). While teacher philosophy and preparation mattered so did grade level and funding-derived computer availability.

The differences between the two types of settings examined here seem to have only modest effects on children's use of computers. This seems to be due to the similarity in the provider's attitudes about technology as well as the rules they have about computer use for children. Further, no group of children (based on setting, age or gender) appears to be at a particular disadvantage with regards to computer use in these child care settings. The providers in this 
study report positive attitudes and good computer skill levels. When computers are made available to children it appears that they are made available in appropriate ways that may potentially support positive outcomes. 
Computer Use in Child Care 25

Acknowledgements: We would like to thank the child care providers and administrators who participated in this research. 


\section{References}

Ba, H., Tally, B. and Tsikalas, K. (2002). Children's emerging digital literacies: Investigating home computing in low-and middle-income families. New York, NY: Center for Children and Technology. Retrieved June 17, 2004 from http://www2.edc.org/CCT.

Bennett, C. (2002). Changing education ergonomics. The Proceedings of the XVI Annual International Occupational Ergonomics and Safety Conference. Retrieved June 17, 2004 from http://education.umn.edu/kls/ecee

Bewick, C.J. \& Kostelnik, M. (2004). Educating early childhood teachers about computers. Young Children, 59 (3), 26-29.

Capizzano, J., Adams, G., and Sonenstein, F. (2000). Child care arrangements for children under five: Variation across states. Washington, D.C.: The Urban Institute. Assessing the New Federalism. Policy Brief No B-7.

Clements, D.H. \& Sarama, J. (2003). Young children and technology: What does the research say? Young Children, 58, 34-40.

Cordes, C. and Miller, E. (2000). Fool's gold: A critical look at computers in childhood. College Park, MD: Alliance for Childhood. Retrieved June 17, 2004, from http://www.allianceforchildhood.net/projects/computers

Cornell University Ergonomics Web. Retrieved August 17, 2005 from http://ergo.human.cornell.edu/MBergo/schoolguide.html

Espinosa, L.M., Laffey, J.M., Whittaker, T. and Sheng, Y. (2006). Technology in the home and the achievement of young children: Findings from the early childhood longitudinal study. Early Education and Development, 17, 421-441. 
Fineberg, D.S., and Cassidy, K.W. (2003). Home computers and young children's use of discretionary time. Paper presented at the Society for Research in Child Development, Tampa, Florida. April 2003.

Franklin, C. (2007). Factors that influence elementary teachers' use of computers. Journal of Technology and Teacher Education, 15, 267-293.

Gillespie, R.M. (2002). The physical impact of computers and electronic game use on children and adolescents, a review of the current literature. Work, 18, 249-259.

Jordan, A.B. and Woodard, E.H. (2001). Electronic childhood: The availability and use of household media by 2- to 3-year olds. Zero to Three, 22(2), 4-9.

Judson, E. (2006). How teachers integrate technology and their beliefs about learning: Is there a connection? Journal of Technology and Teacher Education, 14, 581-597.

Knezek, G. A., Christensen, R.W., Miyashita, K.T., and Ropp, M.M. (2000). Instruments for assessing educator progress in technology integration. Denton, TX: Institute for the Integration of Technology into Teaching and Learning. Retrieved June 17, 2004, from http://www.iittl.unt.edu/

Li, X. and Atkins, M.S. (2004). Early childhood computer experience and cognitive and motor development. Pediatrics, 113 (6), 1715-1722.

Lueder, R., and Rice, V.J.B. (2008). Ergonomics for Children: Designing products and places for toddlers to teens. New York: Taylor \& Francis.

Lynch, A. and Juang, L. (2003, April). Log on: Kids and the Internet. Presentation at the biennial meeting of the Society for Research in Child Development, Tampa, FL.

Martin, S., Forsbach-Rothman, T., \& Crawford, C. (2004). Computer availability and use in child care settings. Information Technology in Childhood Education Annual, 121-134. 
McCarrick, K. and Li, X. (2007). Buried treasure: The impact of computer use on young children's social, cognitive, language development and motivation. Association for the Advancement of Computing in Education Journal, 15, 73-95.

National Association for the Education of Young Children (1996). Technology and young children-Ages 3 through 8. Washington, DC: National Association for the Education of Young Children. Retrieved July 29, 2005 from http://www.naeyc.org/about/positions/pdf/PSTECH98.PDF

Rathbun, A.H., West, J., and Hausken, E.G. (2003). Young children's access to computers in the home and at school in 1999 and 2000, NCES 2003-036. Washington, DC: U.S. Department of Education, National Center for Education Statistics. Retrieved June 17, 2004, http://nces.ed.gov/pubs2003/2003036.pdf.

Rideout, V.J., Vandewater, E.A., and Wartella, E.A. (2003). Zero to Six: Electronic media in the lives of infants, toddlers and preschoolers. Washington, DC: The Henry J. Kaiser Family Foundation. Retrieved July 29, 2005 from http://www.kff.org/

Robinson, L. (2003). Technology as a scaffold for emergent literacy: Interactive storybooks for toddlers. Young Children, 58, 42-48.

Roderman, L.S. (2002, May). Technology and the very young: Lapware, smart toys and beyond. Palo Alto, California: Computer Professionals for Social Responsibility. Retrieved July 30, 2004 from http://archive.cpsr.net/essays/2002/2ed11.html.

Roschelle, J.M., Pea, R.D., Hoadley, C.M., Gordin, D.N., and Means, B.M. (2000). Changing how and what children learn in school with computer-based technologies. The Future of Children, 10(2), 76-97. 
Schmidt, M.E., Bickham, D., King, B., Slaby, R., Branner, A. C., \& Rich, M. (2005). The effects of electronic media on children ages zero to six: A history of research. . Washington, DC: The Henry J. Kaiser Family Foundation. Retrieved July 29, 2005 from http://www.kff.org/

Shields, M.K., and Behrman, R.E. (2000). Children and computer technology: Analysis and recommendations. The Future of Children, 10(2), 4-30.

Wartella, E., Caplovitz, A.G., and Lee, J.H. (2004). From Baby Einstein to Leapfrog, from Doom to The Sims, from instant messaging to internet chat rooms: Public interest in the role of interactive media in children's lives. Social Policy Report, 18 (4), 1-19.

Wartella, E., O’Keefe, B., and Scantlin, R. (2000). Children and interactive media: A compendium of current research and directions for the future. Menlo Park, CA: Markle Foundation. Retrieved June 17, 2004 from http://www.markle.org.

Weinberger, N. \& Stein, K. (In press). Early competitive game playing in same- and mixedgender peer groups. Merrill-Palmer Quarterly.

Yelland, N. (2005). The future in now: A review of the literature on the use of computers in early childhood education (1994-2004). Association for the advancement of Computing in Education Journal, 13, 201-232. 
Table 1. Number of Children in Child Care

Center Based Family Based Total

Boys Under 1

32

16

48

32

11

43

Girls Under 1

Boys -1 year old

69

13

82

Girls -1 year old

47

17

64

Boys -2 year old

114

27

141

Girls -2 year old

107

18

125

Boys -3 year old

290

37

327

Girls -3 year old

260

22

282

Boys -4 year old

344

17

361

Girls -4 year old

301

14

315

Boys -5 year old

140

29

169

Girls -5 year old

134

13

147

Boys -6 year old \& older

214

31

245

Girls -6 year old \& older

226

28

254

Total

2310

293 2603 
Table 2. Provider Education, Technology Ratings, and Information Technology Attitudes

\begin{tabular}{|c|c|c|c|c|}
\hline & $\begin{array}{l}\text { Center } \\
\text { Based } \\
\underline{\mathrm{M}}(\mathrm{SD})\end{array}$ & $\begin{array}{l}\text { Family } \\
\text { Based } \\
\underline{\mathrm{M}}(\mathrm{SD})\end{array}$ & $\begin{array}{l}\text { Total } \\
\underline{\mathrm{M}}(\mathrm{SD})\end{array}$ & $\begin{array}{l}\text { MANOVA } \\
\text { Results } \\
\text { F(p) }\end{array}$ \\
\hline $\begin{array}{c}\text { Education } \\
1=\text { High } \text { School/Equivalent to } 5= \\
\text { Graduate Degree }\end{array}$ & $4.03(0.69)$ & $2.33(1.44)$ & $3.07(1.28)$ & $40.21(.000 * *)$ \\
\hline $\begin{array}{c}\text { Technology Ratings } \\
\text { Level of Technological Adoption } \\
\text { 1=Non-Use.....8=Renewal }\end{array}$ & $4.97(1.9)$ & $5.17(2.01)$ & 5.08 (1.96) & $.993(.323)$ \\
\hline $\begin{array}{c}\text { Technological Proficiency } \\
1=\text { least to } 5=\text { most } \\
(28 \text { Questions; } \alpha=.964)\end{array}$ & $3.88(.85)$ & $3.98(.71)$ & $3.93(.77)$ & $.108(.743)$ \\
\hline $\begin{array}{c}\text { Impact of Technology on Children } \\
1=\text { negative } \ldots 5=\text { positive } \\
\text { (16 Questions; } \alpha=.905)\end{array}$ & $3.40(.69)$ & $3.50(.64)$ & $3.46(.66)$ & $.095(.759)$ \\
\hline \multicolumn{5}{|l|}{$\begin{array}{c}\text { Attitudes Toward Technology } \\
1=\text { negative } 7=\text { positive }\end{array}$} \\
\hline $\begin{array}{l}\text { Attitude to E-mail } \\
\text { (11 Questions; } \alpha=.913)\end{array}$ & $5.43(.912)$ & 4.87 (1.19) & $5.12(1.11)$ & $6.4\left(.014^{*}\right)$ \\
\hline $\begin{array}{l}\text { Attitude to WWW } \\
\text { (11 Questions; } \alpha=.929)\end{array}$ & $6.12(.73)$ & $5.50(1.21)$ & $5.76(1.28)$ & $9.86(.002 * *)$ \\
\hline $\begin{array}{l}\text { Attitude to Multi-Media } \\
\text { (11 Questions; } \alpha=.952)\end{array}$ & $4.83(1.32)$ & $4.87(1.08)$ & $4.85(1.18)$ & $.322(.572)$ \\
\hline $\begin{array}{l}\text { Attitude to Computers for Work } \\
\qquad(11 \text { Questions; } \alpha=.931)\end{array}$ & $5.72(.96)$ & $5.29(1.12)$ & $5.48(1.13)$ & $6.85(.011 *)$ \\
\hline $\begin{array}{l}\text { Attitude to Children's Use of } \\
\text { Computers in Child Care } \\
(11 \text { Questions; } \alpha=.942)\end{array}$ & $5.45(.99)$ & $5.25(1.17)$ & $5.34(1.28)$ & $1.53(.220)$ \\
\hline $\begin{array}{l}\alpha=\text { Chronbach's alpha } \\
* \text { Significant differences at } 0.05 \\
* * \text { Significant differences at } 0.01 \\
\text { F and p based on MANOVA (Overall F=60 }\end{array}$ & $\left..000^{* *}\right)$ & & & \\
\hline
\end{tabular}

